\title{
Research of Antarctic Ozone Circumpolar Vortex using Satellite Data
}

\author{
Valentin B. Kashkin* \\ Siberian Federal University \\ 79 Svobodny, Krasnoyarsk, 660041, Russia
}

Received 22.11.2014, received in revised form 18.12.2014, accepted 12.01.2015

\begin{abstract}
A model of Antarctic ozone circumpolar vortex (CV) is proposed with gradient wind as a base. It was found that at time of the vortex formation the total ozone maximum is concentrated in the $45^{\circ} \mathrm{S}$ and the CV average diameter is $9000 \mathrm{~km}$. It was confirmed with measurements from satellite data. It is shown that at the time of the vortex formation there is ozone redistribution between the inner region of $C V$ and its periphery, it furthers to the Antarctic ozone anomaly appearance. The zonal wind speed in $C V$ was evaluated theoretically and experimentally.
\end{abstract}

Keywords: ozone hole, circumpolar vortex, Coriolis force, zonal wind.

\section{Исследование антарктического озонового циркумполярного вихря с использованием данных спутникового дистанционного зондирования}

\section{В.Б. Кашкин}

Сибирский федеральный университет Россия, 660041, Красноярск, пр. Свободньій, 79

Построена модель антарктического ичиркумполярного вихря (ЦВ) в эпоху его формирования весной на основе сиенария с градиентным ветром. Установлено, что в это время максимум общего содержания озона приходится на $45^{\circ}$ ю.и., а средний диаметр ЦВ составляет 9000 км. Это подтверждается спутниковыми данными. Показано, что при формировании ЦВ происходит перераспределение озона между внутренней областью ЦВ и его периферией, что способствует появлению антарктической озоновой аномалии. Оценены теоретически и экспериментально скорости зонального ветра в ЦВ.

Ключевые слова: озоновая дыра, ииркумполярный вихрь, сила Кориолиса, зональный ветер.

В последние десятилетия проблему озонового слоя Земли ставят в число наиболее важных глобальных экологических проблем. Без озонового слоя жизнь на Земле в ее современном

C) Siberian Federal University. All rights reserved

* Corresponding author E-mail address: rtcvbk@rambler.ru 
виде невозможна. Озон - малая атмосферная примесь $\left(10^{-6}-10^{-5} \%\right.$ по объему), образующая сферический слой высотой около 90 км. Больше всего озона содержится на высоте 15-17 км в полярных широтах, на высоте 20-21 км в средних широтах и на высоте 26-27 км в тропиках, которые являются главной областью образования озона, откуда озон переносится в средние и полярные широты.

Если собрать весь озон в слой при давлении 1013,25 гПа и температуре 288,15 K, то толщина этого слоя, т.е. общее содержание озона (ОСО), составит около 3 мм или 300 единиц Добсона (е.Д.) [1]. 1 е.Д. $=10^{-5}$ м. ОСО обычно измеряют по поглощению и рассеянию солнечной радиации в УФ-диапазоне. Источником данных о ежедневном глобальном распределении ОСО являются искусственные спутники Земли.

В 80-х гг. ХХ в. тревогу общественности вызвала информация об истощении озонового слоя, росте интенсивности УФ-радиации и об открытии антарктической озоновой аномалии (AOA), известной также как антарктическая озоновая дыра. Всемирная метеорологическая организация приняла план действий по защите озонового слоя от антропогенного воздействия, были подписаны Венская конвенция и Монреальский протокол об охране озона. Документы ратифицировали большинство стран - членов ООН.

Озоновыми аномалиями принято называть области с ОСО ниже уровня 220 е.Д. Такие области наблюдаются регулярно над Антарктикой в весенний период в течение 2-3,5 месяца, особенно в сентябре и октябре. Аномалии могут иметь площадь более 20 млн км². В Арктике озоновые аномалии - очень редкое явление, они кратковременны (от нескольких дней - до 2-3 недель) и имеют небольшую площадь (это «мини-дыры»).

Молекулы озона в естественных условиях образуются и разрушаются под действием различных естественных и антропогенных факторов. В отличие от конца XX в., в настоящее время ОСО в атмосфере начинает немного увеличиваться, но антарктическая озоновая аномалия остается в прежних размерах [1].

На рис. 1 показаны изображения озонового слоя в Южном полушарии за 7 сентября и 27 декабря 2010 г., построенные по данным спутника AURA (сканер OMI) [2]. Эти данные содержат значения ОСО на сетке $1^{\circ} \times 1^{\circ}$ для $89,5^{\circ}$ ю.ш. $-89,5^{\circ}$ с.ш. и $179,5^{\circ}$ в.д. $-179,5^{\circ}$ з.д. В зимневесенний период некоторые приполярные области не освещены Солнцем, и потому спутниковые данные об ОСО для этих областей отсутствуют. В файле за 7 сентября 2010 г. данные об

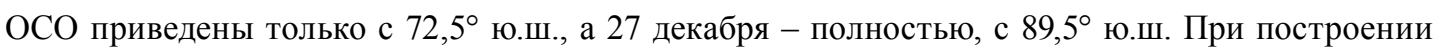
изображения использовалась интерполяция по методу Krige и заполнение пустых пикселов в области полюса в пакете Surfer-8 [3].

Весной, в сентябре, в Антарктике образуется так называемый циркумполярный вихрь (ЦВ). На рис. 1 изображение ЦВ содержит кольцо зеленого цвета - с ОСО от 300 до 460 е.Д., внутри которого находится АОА с пониженным содержанием озона, минимальное ОСО составило 160220 е.Д. Снаружи кольца можно видеть изображение синего цвета - это область экватора с ОСО в 250-270 е.Д. 27 декабря АОА уже почти заполнена озоном. Обращает на себя внимание тот факт, что максимальное содержание ОСО в ЦВ 7 сентября более чем на 90 е.Д. превышает максимальное ОСО во всем озоновом слое 27 декабря. Со стороны экватора кольцо имеет вид искаженной окружности, причиной этого могут быть планетарные волны. Циркумполярные вихри, формирующиеся над зимне-весенним полюсом, являются антициклонами. 


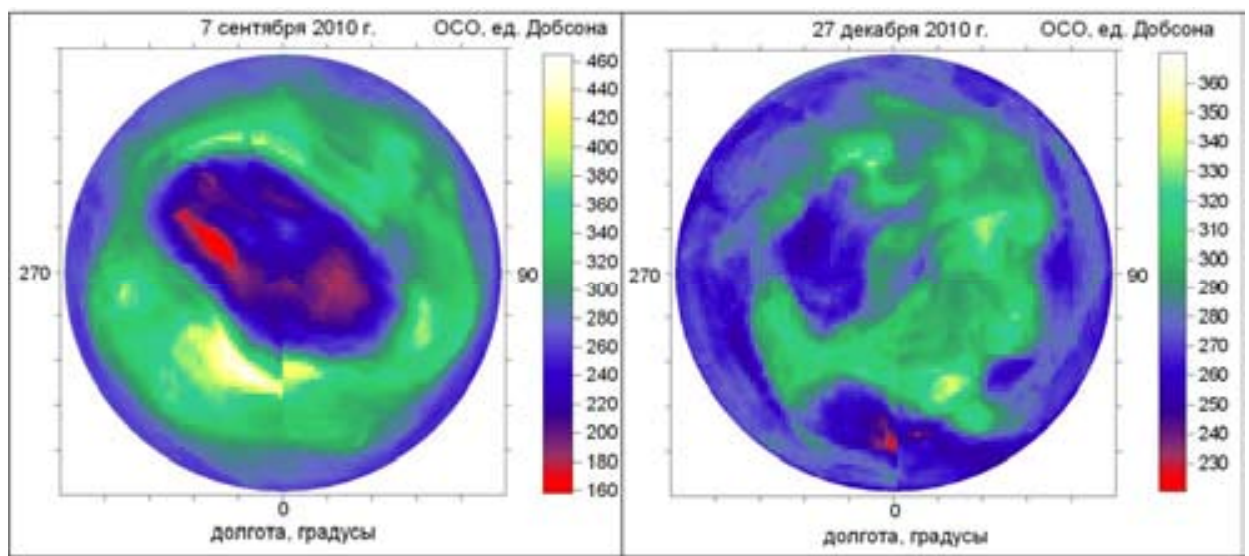

Рис. 1. Изображение озонового слоя в Южном полушарии по спутниковым данным

Впервые сильное весеннее истощение озона над Антарктидой было отмечено во время Международного геофизического года 1957-58 гг. ОСО над станцией Halley Bay (Великобритания) [4]. Уменьшение количества озона в весенний период наблюдали также российские исследователи на антарктических станциях с 1974 г. [5].

Настоящая история Антарктической озоновой аномалии началась в 1985 г. со статьи в журнале «Nature» [6]. Её авторы обнаружили на станции Halley Bay в 1984 г. понижение ОСО на 40 \% по сравнению с предыдущим годом. Это явление они связали с усилением хлорного каталитического цикла разрушения озона из-за техногенных хлорфторуглеродов (фреонов). «Фреоновая» концепция легла в основу упомянутых Венской конвенции и Монреальского протокола, регламентирующих вначале сокращение, а потом и полное запрещение производства хлорфторуглеродов и других озоноразрушающих веществ. К слову, фреоны уже десятилетия не выпускаются в заметных объемах, но, тем не менее, АOА периодически возникает каждый год.

Несмотря на большое количество экспериментальных и теоретических исследований, реальные причины убыли озона в области антарктической озоновой аномалии до сих пор окончательно не установлены, дискуссия о природе этих явлений продолжается. Актуален поиск новых механизмов образования аномалий в озоновом слое.

Е.А. Жадин с соавторами [7] исследовал связь изменений циркуляции атмосферы в Южном полушарии и ОСО на основе расчета стратосферного момента импульса. Было выяснено, что летом 1980 г. произошел резкий переход циркуляции стратосферы к новому режиму, что способствовало образованию озоновой аномалии над Антарктидой.

В.Л. Сывороткин с соавторами [8] изучил разрушение озонового слоя флюидными потоками из рифтовых зон. Эти потоки содержат в основном водород и метан, которые способствуют разрушению озона в стратосфере.

Воздействие космических лучей на озон средней атмосферы было рассмотрено А.А. Криволуцким с соавторами [9]. После мощных вспышек на Солнце заряженные частицы ионизируют газы верхних слоев полярной атмосферы, что приводит к образованию молекул окиси азота и гидроксильных радикалов, разрушающих озон. 
Наиболее вероятный механизм возникновения весенней озонной аномалии в Антарктике предложен В.В. Зуевым [10, 11]. Циркумполярный вихрь создает барьер, блокирующий перенос стратосферного озона из тропических и средних широт. В стратосфере внутри вихря при температуре ниже минус $78{ }^{\circ} \mathrm{C}$ формируются аэрозольные образования - полярные стратосферные облака (ПСО). На поверхности ПСО протекают гетерогенные реакции, в которых хлор переходит в активные формы $\left(\mathrm{Cl}_{2}\right.$ и $\left.\mathrm{ClO}\right)$. С появлением солнечного излучения запускается хлорный цикл разрушения озона.

Источником хлора в Антарктике является Эребус - один из самых активных вулканов на Земле, периодически выбрасывающий столб газов, которые поднимаются в стратосферу на высоту до 20 км. В начале 80-х гг. ХХ в. произошло аномальное усиление активности вулкана, в 1983 г. выбросы $\mathrm{SO}_{2}$ и $\mathrm{HCl}$ резко возросли [12], более чем в три раза превышая современный уровень. В 1979-1981 гг. площадь АОА была менее 1 млн км², в 1982-1989 гг. резко увеличилась, достигнув к 1997 г 20 млн км². Высокая активность Эребуса перевела АОА из одного состояния в другое. Авторы [11] считают, что уменьшение АOА возможно только при резком снижении или полном прекращении активности вулкана, так как современная величина выбросов достаточна для протекания реакций разрушения озона и сохранения существующих масштабов озоновой дыры.

Динамика формирования антарктического ЦВ была рассмотрена В.Б. Кашкиным, Р.Г. Хлебопросом и Т.В. Рублевой в [13]. Разработан метод слежения за воздушными потоками в стратосфере по спутниковым данным об озоне, изучено перемещение масс озона в области АОА [14]. Показано, что в начале весны озон из внутренней части ЦВ перемещается в кольцо вихря, что способствует формированию озоновой аномалии. В развитие этого подхода ниже рассмотрено влияние градиента геопотенциальной высоты на формирование ЦВ и на перемещение воздуха (вместе с озоном) внутри ЦВ.

На рис. 2 приведена карта геопотенциальной высоты ${ }^{1}$ на изобарическом уровне 100 гПа в координатах $60^{\circ}-80^{\circ}$ ю.ш., $50^{\circ}-80^{\circ}$ в.д. Использованы данные дистанционного зондирования атмосферы с сайта NOAA [15]. В начале весны Солнце прогревает стратосферу вблизи Южного полюса на $78^{\circ}$ ю.ш., температура здесь повышается с минус 78 до минус $73^{\circ} \mathrm{C}$, растут давление

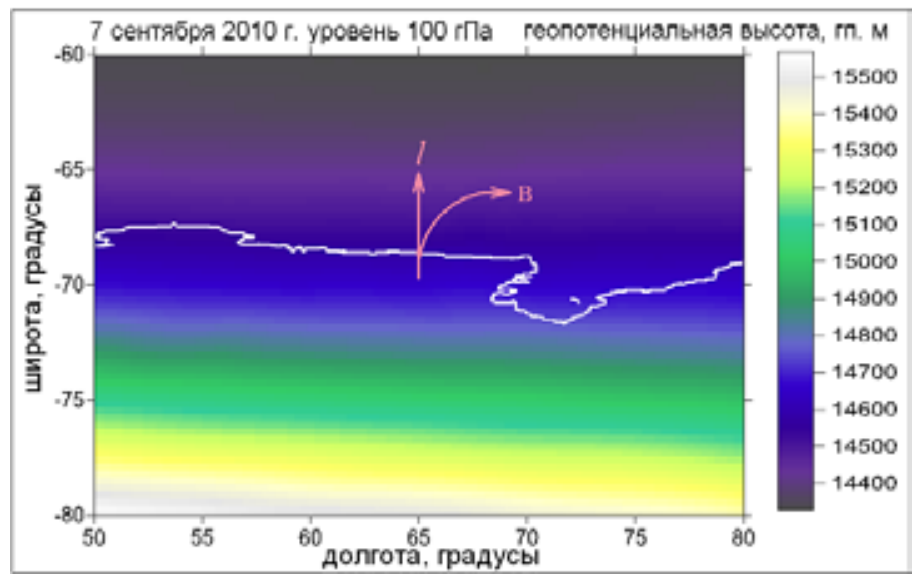

Рис. 2. Карта геопотенциальной высоты. Белая линия обозначает береговую линию 
и геопотенциальная высота (ГПВ). Возникает горизонтальный градиент ГПВ в направлении $l$ к средним широтам, что показано стрелкой на рис. 2. Рассмотрим некоторый объем воздуха массой $m$, содержащего озон, на изобарическом уровне $p$ в области высокой ГПВ. Так, в стратосфере воздух разрежен, нет смысла учитывать силу турбулентного трения, которая много

меньше рассматриваемых ниже сил. На объем воздуха действует сила тяжести $\mathrm{G}=m g \frac{\partial Z}{\partial l}$, $g$ - ускорение свободного падения. Величина $\frac{\partial Z}{\partial l}$ по модулю равна проекции градиента ГПВ на направление $l$.

Под действием силы тяжести указанный объем начинает ускоренное движение в направлении $l$. Из-за отклоняющей силы вращения Земли (силы Кориолиса К) появляется смещение объема к востоку в направлении стрелки В. Общее направление изменяется, это будет продолжаться до тех пор, пока движущийся объем не повернется на $90^{\circ}$ относительно $l$, а сила Кориолиса не уравновесит $\mathrm{G}$, т.е. $\mathrm{G}=\mathrm{K}$. Ускоренное движение превратится в равномерное и прямолинейное в направлении В. Такое движение в установившемся режиме в физике атмосферы называют геострофическим ветром [16].

Сила Кориолиса равна $\mathbf{K}=2 m \cdot[\boldsymbol{\Omega} \times \mathrm{v}]$, где $\boldsymbol{\Omega}-$ вектор угловой скорости вращения Земли, направленный вдоль оси вращения к Северному полюсу; $\mathbf{v}-$ вектор скорости объема воздуха в установившемся режиме. Горизонтальная составляющая силы Кориолиса в Южном полушарии равна $\mathrm{K}=2 \Omega v \sin |\varphi|$, где $\Omega=2 \pi \cdot 1,157 \cdot 10^{-5} \mathrm{c}^{-1} ; v$ - модуль вектора скорости объема воздуха; $\varphi$ - географическая широта, которая для Южного полушария обычно считается отрицательной. Таким образом,

$$
g \frac{\partial Z}{\partial l}=2 \Omega v \sin |\varphi|
$$

На рис. 2 показана часть карты ГПВ Антарктики. На карте ГПВ всей Антарктики и её окружения область с максимальной геопотенциальной высотой сконцентрирована вблизи Южного полюса, объемы воздуха движутся во все стороны от полюса к северу, поворачиваясь к востоку и выходя на круговые траектории. На каждый объем начинает действовать дополнительная центробежная сила $\mathrm{F}_{\text {u }}=m \frac{v^{2}}{R_{v}}$, в антициклоне она направлена туда же, куда и сила G. Здесь $R_{v}=R_{3} \cdot \cos \varphi$ - радиус окружности, по которой вращается объема воздуха, $R_{3}=6378$ км экваториальный радиус Земли.

Уравнение баланса сил принимает вид $[16,17]$

$$
\begin{gathered}
\mathrm{G}+\mathrm{F}_{\text {ч }}=\mathrm{K}, \\
-m g \frac{\partial Z}{\partial l}+m \frac{v^{2}}{R_{v}}=m \cdot 2 \Omega v \sin \varphi .
\end{gathered}
$$

Тормозящая сила Кориолиса уравновешивает силы $\mathrm{G}$ и $\mathrm{F}_{\text {ц }}$, объем воздуха принимает в горизонтальное движение по криволинейной траектории с постоянной скоростью $v$. Такое движение в установившемся режиме называют градиентным ветром. 
Уравнение (2) преобразуется к виду

$$
-g \frac{\partial Z}{\partial l} R_{3} \cos \varphi+v^{2}=2 \Omega v \sin \varphi R_{3} \cos \varphi
$$

Сила Кориолиса в правой части (3) умножена на радиус окружности $R_{v}=R_{3} \cos \varphi$, это изменяет характер зависимости от широты. Правая часть приводится к виду $\Omega v R_{3} \sin 2 \varphi$. При значении $\varphi=45^{\circ}$ правая часть (2) максимальна и равна $\Omega v R_{3}$, при наличии центробежного ускорения на этой широте присутствует наибольшее тормозящее действие силы Кориолиса. Поэтому следует ожидать, что весной вблизи широты $45^{\circ}$ сконцентрируются массы воздуха (вместе с озоном), перенесенные из приполярной зоны, вблизи этой широты возникает кольцо озона. Происходит перераспределение озона между внутренней частью ЦВ и кольцом, количество озона в котором растет. ОСО во внутренней части уменьшается, что является одной из причин образования озоновой дыры. Позже, с середины октября, внутренняя часть ЦВ начинает заполняться озоном, который движется как из кольца, так и из средних и тропических широт.

Обработка спутниковых данных об озоне подтверждает этот вывод. На рис. 3 показано распределение ОСО по широте за три весенних дня в разные годы, когда формировался циркумполярный вихрь, увеличивалось ОСО в кольце и уменьшалось ОСО внутри него. По характеру три графика похожи друг на друга, максимумы практически совпадают, их абсциссы близки к $45^{\circ}$. Особенностью графиков также является отсутствие данных для широт 77,5 ю.ш. и более высоких, так как на этих широтах стратосфера не была освещена Солнцем. На рис. 3 дан график за 7 сентября 2010 г., соответствующее изображение озонового слоя приведено на рис. 1, слева. График за 27 декабря на рис. 3 показывает распределение ОСО по широте в начале лета Южного полушария, когда внутренняя часть ЦВ почти заполнена, ему соответствует изображение озонового слоя на рис. 1, справа.

При построении рис. 3 использованы данные о так называемых зональных средних (zonal means), приведенные на сайте NASA [2]. Зональные средние - результат разбиения спутниковых данных об ОСО по широте на кольца шириной в $5^{\circ}$, по долготе кольцо охватывает $360^{\circ}$. Вычислено среднее значение ОСО в кольце.

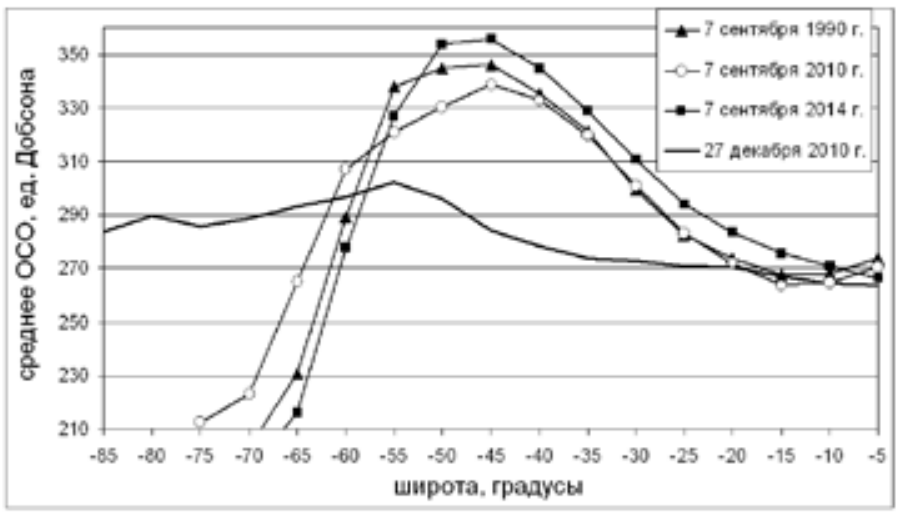

Рис. 3. Широтное распределение ОСО

$$
-243-
$$


В формировании ЦВ принимают участие и другие процессы. В тропосфере над полюсами преобладают холодные полярные восточные ветры, а в средних широтах - теплые западные. В результате у шестидесятых широт пролегает полярный фронт, вдоль которого проходит температурный градиент, усиливающийся в зимний период. Увеличение температурного градиента у поверхности Земли вызывает усиление градиента давления в воздухе, это приводит к ускорению западных стратосферных ветров [16].

Зададимся градиентом геопотенциальной высоты $\frac{\Delta Z}{\Delta l}$. В физике атмосферы обычно вычисляют градиент при $\Delta l=1^{\circ}$ [17]. На рис. 2 градиент на широтах от $-70^{\circ}$ до $-60^{\circ}$ равен 16 гп. м на градус широты, анализ показал, что на $-50^{\circ}$ он составляет 33 гп. м/град, а на $-45^{\circ}$ составляет 53 гп. м/град. Вдоль меридиана $1^{\circ}$ соответствует 111 км.

Вычислим, какую скорость $v_{1}$ получит объем воздуха, двигаясь с высоты $\Delta \mathrm{Z}=53$ м. Поскольку трение не учитывается, то достаточно рассмотреть падение вертикально вниз.

$$
v_{1}=\sqrt{g \Delta Z}=32,1 \mathrm{M} / \mathrm{c} .
$$

Согласно (1), скорость геострофического ветра $v_{2}$ на широте $45^{\circ}$ равна

$$
v_{2}=\frac{g}{2 \Omega \sin 45^{\circ}} \frac{\Delta Z}{\Delta l}=45,2 \mathrm{~m} / \mathrm{c} .
$$

Скорость градиентного ветра $v_{3}$ на широте $45^{\circ}$ можно вычислить, если решить квадратное уравнение:

$$
v^{2}-\Omega v R_{3}-g \frac{\Delta Z}{\Delta l} R_{3} \cos 45^{\circ}=0 .
$$

Получаем: $v_{3}=41,5$ м/с. Все три скорости оказались близкими друг к другу.

Ранее нами были выполнены измерения скорости зонального ветра в стратосфере по спутниковым данным об ОСО $[13,14]$. Зональный ветер в атмосфере движется вдоль параллели, градиентный ветер является его теоретической оценкой.

При сравнении двух изображений, таких как на рис. 1, слева, полученных с разницей в один день, было замечено, что второе изображение повернуто относительно первого на некоторый угол. Массив данных ОСО представляет собой некоторое случайное поле. Для оценки смещения за сутки поле за текущий и предыдущий день разбивается на фрагменты в $5^{\circ}$ по широте и в $360^{\circ}$ по долготе, в которые попадает 1800 отсчетов ОСО. Фрагмент за предыдущий день поворачивается по кругу с шагом $1^{\circ}$ по долготе и сдвигается с шагом $1^{\circ}$ по широте в направлении от экватора или к экватору (меридиональный сдвиг). На каждом шаге оценивается коэффициент взаимной корреляции $R$ между значениями ОСО в фрагменте за текущий и за предыдущий дни.

Поворот и сдвиг, при которых коэффициент корреляции максимален и достигает иногда $R=0,95-0,98$, соответствуют средней по полушарию суточной зональной и меридиональной скорости движения фрагмента. Ниже рассмотрен пример, здесь максимум коэффициента корреляции $R$ был близок к 0,8873 . При объеме выборки в 1800 отсчетов и нормальном законе ее распределения истинное значение $R=0,8873$ с вероятностью $97,5 \%$ лежит между 0,876 и 0,895 


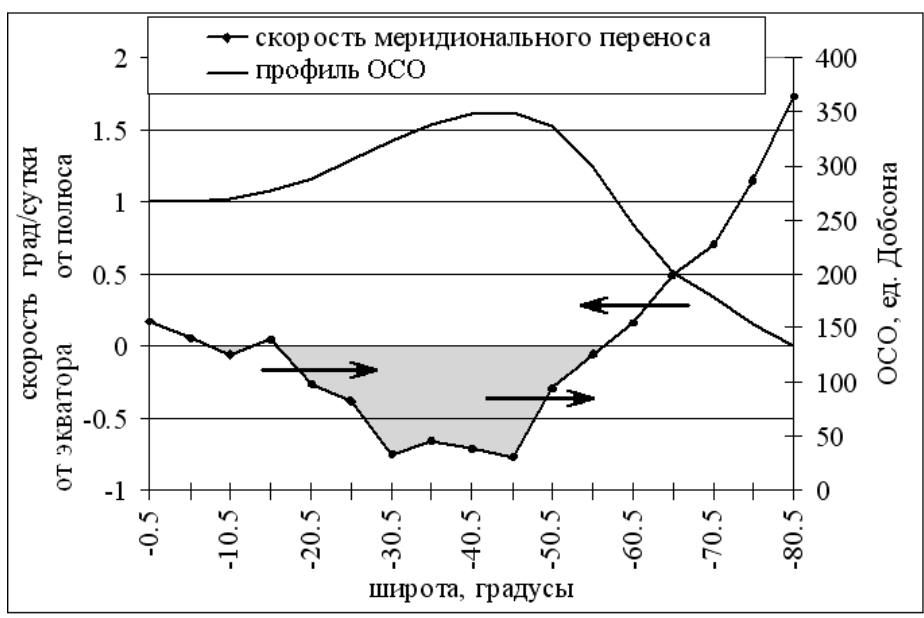

Рис. 4. Зависимость скорости меридионального переноса озона от широты и ОСО в Южном полушарии в сентябре

[18]. Это указывает на статистическую значимость полученных результатов, на чувствительность метода к поворотам и сдвигам.

На рис. 4 приведена зависимость меридиональной скорости озона от широты за первую половину сентября 1997-2008 гг. по усредненным данным. Здесь же показан средний профиль общего содержания озона для весны 2006 г. Максимум ОСО (360 е.Д.) приходится на коль-

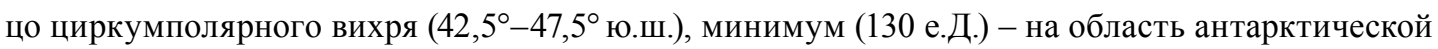
озоновой дыры (широта $-70^{\circ}$ и выше). Положительным значениям скорости (верхняя стрелка) соответствует приток масс озона из внутренней области ЦВ в кольцо циркумполярного вихря, отрицательным (нижние стрелки) - отток озона из области экватора в кольцо ЦВ и из кольца во внутреннюю область. Из приведенных зависимостей следует, что происходит перенос из приполярной области в средние широты, т.е. во время формирования озоновой дыры возникает перераспределение масс озона между приполярной областью и кольцом, примыкающим к широте $-45^{\circ}$. Имеет место также перенос озона из экваториальной области в средние широты (левая стрелка), но в начале сентября он выражен слабо.

Для сравнения с расчетом значения скорости зонального ветра были преобразованы в единицы (м/с). По расчету на широте $-45^{\circ}$ скорость градиентного ветра $v_{3}=41,5$ м/с, по результатам измерений скорость зонального ветра равна 13 м/с. Расхождение вполне объяснимо. Градиентный ветер учитывает только горизонтальное движение воздуха; на зональную скорость влияет восточный ветер, который существует в теплую половину года в стратосфере на высоте 15-27 км [16]. Возможны и другие причины, также связанные с общей циркуляцией атмосферы.

В заключение следует отметить, что образование циркумполярного вихря в Южном полушарии в соответствии с моделью градиентного ветра, по-видимому, происходило и раньше, в частности, в то время, когда антарктическая озоновая аномалия отсутствовала или имела малые размеры, например в 1979 и 1980 гг. Резкое увеличение площади АОА в последующие годы, вероятнее всего, связано с ростом активности вулкана Эребус.

$$
-245-
$$




\footnotetext{
Геопотенциальная высота $\Phi$ - это отношение геопотенциала к стандартному ускорению свободного падения $\mathrm{g}_{0}=9,80665 \mathrm{~m} / \mathrm{c}^{2}$. Геопотенциалом уровня $\Phi^{*}$ принято называть работу, которую необходимо совершить, чтобы поднять единицу массы в поле силы тяжести от уровня моря до уровня $\Phi^{*}$. Единицей геопотенциальной высоты является геопотенциальный метр (гп. м), который до высоты 30 км практически не отличается от обычного метра [16].
}

\section{Список литературы}

[1] World Meteorological Organization/Global Ozone Research and Monitoring Project - Report No. 56. http://www.wmo.int/pages/prog/arep/gaw/ozone_2014/ozone_asst_report.html

[2] ftp://toms.gsfc.nasa.gov/pub/omi/data/ozone/

[3] Силкин К.Ю. Геоинформационная система Golden Software Surfer 8. Воронеж: Воронеж. гос. ун-т, 2008. $66 \mathrm{c}$.

[4] Звягинцев А.М., Зуев В.В., Кручениикий Г.М., Скоробогатый Т.В. // Исследование Земли из космоса. 2002. № 3. С. 29-34.

[5] Радионов В.Ф., Сабир Е.Е., Мишин А.А. // Исследования и охрана окружающей среды Антарктики: тез. докл. науч. конф. СПб., 2002. С. 89-91.

[6] Farman J.C., Gardiner B.G., Shanklin J.D. // Nature. 1985. V. 315. № 6016. P. 207-210.

[7] Jadin E.A., Kondratyev K.Ya., Beroyukov V.I., Vargin P.N. // International Journal of Remote Sensing. 2006. V. 27. № 16. Р. 3467-3478.

[8] Сывороткин, В.Л. // Химия и жизнь. 2001. № 3. С. 14-17.

[9] Криволуикий А.А., Репнев А.И. // Геомагнетизм и аэрономия. 2012. Т. 52. № 6. C. $723-754$.

[10] Зуев В.В., Зуева Н.Е., Савельева Е.С. // Оптика атмосферы и океана. 2014. Т. 27. № 5. C. $407-412$.

[11] Савельева Е.С., Зуев В.В., Зуева Н.Е. // Химия в интересах устойчивого развития. 2014. T. 22. № 5. C. 541-547.

[12] Zreda-Gostynska G., Kyle P.R., Finnegan D.L. // Geophys. Res. Lett. 1993. V. 20. № 18. P. $1959-1962$.

[13] Кашкин В.Б., Хлебопрос Р.Г., Рублева Т.В. // Инженерная экология. 2009. № 4. С. 18-32.

[14] Кашкин В.Б., Рублева Т.В. // Оптика атмосферы и океана. 2014. № 9. С. 826-832.

[15] http://ready.noaa.gov/ready2-bin/extract/extracta.pl

[16] Матвеев Л.Т. Курс общей метеорологии. Физика атмосферы. Л.: Гидрометеоиздат, 1984. $752 \mathrm{c}$.

[17] Fleagle R.F., Businger J.A. An Introduction to Atmospheric Physics. New York, London, Toronto: Academic Press, 1980. P. 151-200.

[18] Большев Л.Н., Смирнов Н.В. Таблицы математической статистики. М.: Наука, 1985. $464 \mathrm{c}$. 